\title{
Guillaume le Conquérant face aux défis, études réunies par Huguette Legros
}

G. Matteo Roccati

\section{CpenEdition}

\section{Journals}

Édition électronique

URL : https://journals.openedition.org/studifrancesi/4595

DOI : 10.4000/studifrancesi.4595

ISSN : 2421-5856

Éditeur

Rosenberg \& Sellier

\section{Édition imprimée}

Date de publication : 1 avril 2012

Pagination : 120

ISSN : 0039-2944

\section{Référence électronique}

G. Matteo Roccati, « Guillaume le Conquérant face aux défis, études réunies par Huquette Legros », Studi Francesi [En ligne], 166 (I | LVI) | 2012, mis en ligne le 30 novembre 2015, consulté le 19 novembre 2021. URL : http://journals.openedition.org/studifrancesi/4595 ; DOI : https://doi.org/10.4000/ studifrancesi.4595

Ce document a été généré automatiquement le 19 novembre 2021.

\section{cc) (i) $\odot$}

Studi Francesi è distribuita con Licenza Creative Commons Attribuzione - Non commerciale - Non opere derivate 4.0 Internazionale. 


\title{
Guillaume le Conquérant face aux défis, études réunies par Huguette Legros
}

\author{
G. Matteo Roccati
}

\section{RÉFÉRENCE}

Guillaume le Conquérant face aux défis, études réunies par Huguette LEGROS, Orléans,

Paradigme, 2008 («Medievalia», 66), pp. 200.

1 Le volume réunit les contributions présentées au cours d'un colloque qui s'est tenu en septembre 2005 à Dives-sur-Mer. Penny ELEY, L'image du Conquérant et de ses opposants chez Benoît de Sainte-Maure, pp.17-30, propose l'étude des épisodes de jeunesse, précédant l'invasion de l'Angleterre. Jean-Guy GOUTTEBROZE, Le songe du roi Édouard dans la «Vita regis Aedwardi qui apud Westmonasterium requiescit: un propos équivoque, pp. 31-49, analyse avec acuité la signification politique du songe, dont l'ambiguïté s'est prêtée à plusieurs réinterprétations en fonction de l'évolution de la situation. Claude HERZFELD, «Vérité historique» \& vérité humaine: le cas Guillaume traité par Wace, pp. 51-68, brosse les grandes lignes de la présentation du personnage chez Wace. Denis HÜE, Guillaume le Conquérant et la Vierge, pp. 69-91, montre comment le culte de l'Immaculée Conception, présent en Angleterre avant la conquête normande et supprimé à sa suite, s'est réimplanté plus tard en s'étendant à la Normandie; Guillaume est alors perçu, d'une manière entièrement mythique, comme le promoteur de ce culte. Stéphane LAînÉ, La Fuite de Valognes: comparaison des différentes versions en langue vernaculaire, pp. 93-134, examine dans les chroniques latines et en langue vernaculaire les récits qui relatent le complot à l'occasion duquel aurait eu lieu la fuite; elle n'apparaît pas dans les textes latins et cet épisode, fondateur de l'autorité du jeune duc, se révèle être une élaboration littéraire. Les contributions de Huguette LEGROS, Naissance d'un héros: de la bâtardise à la légende dans la «Chronique» de Benoit de Sainte-Maure, pp. 135-147, et de Françoise LE SAUX, Guillaume l'illégitime? La bâtardise de Guillaume le Conquérant dans le «Roman de Rou» de Wace, pp.149-163, examinent comment dans les deux textes est 
présentée la naissance illégitime de Guillaume, fruit d'une union more danico: sans l'affirmer explicitement, Wace est critique, alors que Benoît réinterprète les faits de manière romanesque, en les présentant comme un signe de l'élection divine. Claude LETELLIER, Robert de Mortain, frère fidèle, pp.165-170, étudie les liens de solidarité de Guillaume et de ses deux demi-frères, Robert et Odon. Laurence MATHEY-MAILLE, La liste des compagnons de Guillaume le Conquérant: un défi à la mémoire, pp. 171-180, fait le point sur la fiabilité des listes établies a posteriori. Enfin André NovÉ, Guillaume dans la mémoire de Dives, pp.181-194, traite de la manière dont a été recréé le souvenir du Conquérant tandis que Gilles susong, À propos du siège de Domfront par Guillaume le Conquérant (1048-1051), pp. 195-198, d'un épisode de son activité militaire. 